\title{
Effect of grain angle on the strain distribution during orthogonal cutting of hinoki (Chamaecyparis obtusa) measured using a digital image correlation method
}

Yosuke Matsuda ${ }^{1 *}$, Yuko Fujiwara ${ }^{2}$ and Yoshihisa Fujii ${ }^{2}$

\begin{abstract}
The strain associated with orthogonal cutting with and against the grain of hinoki (Chamaecyparis obtusa) was measured. Digital image correlation method was used to measure strain distributed in the area within $0.5 \mathrm{~mm}$ of the cutting edge. The relationship between strain and the use of different grain angles $\left(-15^{\circ} \leq \varphi \leq+15^{\circ}\right)$ was investigated. The compressive strain parallel to the cutting direction was detected in the area above the path of the cutting edge regardless of $\varphi$. The tensile strain normal to the cutting direction which generated cleavage ahead of the tool decreased with increasing $\varphi$, when the cutting angle was $30^{\circ}$. While cutting with the grain, shear strain above the path of the cutting edge was positive when the cutting angle was $30^{\circ}$, although it changed to negative with larger cutting angles. The maximum principal strain given by a cutting angle of $50^{\circ}$ was less affected by $\varphi$ than those given by the other cutting angles. The maximum principal strain ahead of the tool was minimized when the cutting angle was $50^{\circ}$ and $+5^{\circ} \leq \varphi \leq+10^{\circ}$.
\end{abstract}

Keywords: Orthogonal cutting, Digital image correlation, Grain angle

\section{Introduction}

Wood cutting is a process that removes part of a workpiece (as a chip) and produces a newly finished surface. Strain is distributed throughout the workpiece as the cutting tool applies its cutting force onto the workpiece. A chip is produced when the destruction of wood occurs because the local strain near the cutting edge of the cutting tool (i.e., the intersection between the rake and the clearance faces of the tool) exceeds the mechanical strength of the wood in that area.

In our previous studies [1, 2], strain distributed within $0.5 \mathrm{~mm}$ from the cutting edge and the residual strain beneath the finished surface in orthogonal cutting parallel to the grain of hinoki (Chamaecyparis obtusa) were measured using a digital image correlation (DIC) method.

\footnotetext{
*Correspondence: yosukem@ffpri.affrc.go.jp

${ }^{1}$ Forestry and Forest Products Research Institute, 1 Matsunosato, Tsukuba, lbaraki 305-8687, Japan

Full list of author information is available at the end of the article
}

The DIC method is a non-contact strain measurement technique [3-7] that has been gaining popularity in the fields of wood research and wood-based material science [8-12]. We have shown that the DIC method is appropriate for measuring strain in wood cutting. We have also shown that the strain distribution within $0.5 \mathrm{~mm}$ of the cutting edge varies depending on the depth of cut and the cutting angle [1]. In addition, the relationships between the residual strain beneath the finished surface and the subsurface damage were evaluated using $\mathrm{X}$-ray computed tomography $[2,13]$. These studies are necessary for determining the wood cutting mechanism from the viewpoint of the strain distribution near the cutting edge.

The grain angle (i.e., the angle between the cutting direction and grain direction on the plane parallel to the grain direction and perpendicular to the finished surface) should be taken into account when evaluating the mechanisms involved in the wood cutting process. The use of an inappropriate grain angle is closely associated with the undesirable generation of fuzzy or torn grain, which is 
a typical machining defect in wood cutting. There have been a few studies that investigated the effect of using different grain angles on the resulting quality of the finished surface [14-16]. Stewart showed that torn grain tended to be produced when the cutting was conducted against the grain, especially where the grain angle was between $-20^{\circ}$ and $0^{\circ}$ [14]. Yamashita demonstrated that the torn grain was the longest where the grain angle was $-5^{\circ}[15]$. Kinebuchi stated that cutting that is done with the grain can result in fuzzy grain if the cutting edge was blunt [16]. Some other studies investigated the relationships between the grain angle and the cutting force [1721]. However, the relationships were different among the studies because the different wood species, cutting speed, rake angle, and/or depth of cut were used [20]. McKenzie and Hawkins [22], and Stewart [23] demonstrated that the type of chip formation [24-26] varied depending on the grain angle, which indicated that the grain angle has important effects on the appearance of the split, chip failure, and removal of the chip. However, the effect of the grain angle on strain distribution near the cutting edge has not been explored in detail; this should be analyzed to prevent machining defects.

Here, we assess the relationships between the grain angle and the strain distribution near the cutting edge in orthogonal cutting with and against the grain. We conducted cuttings with and against the grain of hinoki. The strain distributed within approximately $0.5 \mathrm{~mm}$ of the cutting edge was measured using the DIC method. Different cutting conditions, such as the use of different cutting angles and depths of cut, were used for investigating the relationships between the grain angle and the strain distribution.

\section{Materials and methods \\ Specimens}

The workpieces consist of the heartwood of air-dried hinoki. The dimension of each workpiece was $50 \mathrm{~mm}$, $45 \mathrm{~mm}$, and $5 \mathrm{~mm}$ in longitudinal (L), radial (R), and tangential $(\mathrm{T})$ directions, respectively. We tested various grain angles $(\varphi)$, (i.e., the angle between the cutting direction and grain direction on the plane parallel to the grain direction and perpendicular to the finished surface) ranging from $-15^{\circ}$ to $+15^{\circ}$ with intervals of $5^{\circ}$. Negative $\varphi$ values indicate where the cutting was against the grain, whereas positive $\varphi$ values indicate where the cutting was with the grain. The workpieces had an average air-dried density of $0.36 \mathrm{~g} / \mathrm{cm}^{3}$ and an average moisture content of $10.9 \%$. The average annual ring width was $1.1 \mathrm{~mm}$.

The LR surface was analyzed using the DIC method. It was finished using a rotary planer though fuzzy grain appeared on the surface. The average of surface roughness $(\mathrm{Rz})$ (or the maximum height of roughness profile
JIS B 0601:2013) was $14.9 \mu \mathrm{m}$ at cut-off value of $0.8 \mathrm{~mm}$. The distribution of the fuzzy grain and the arrangement of the tracheid and ray tissue showed a random speckle pattern, which is necessary for the application of the DIC method [6, 7]. Therefore, no artificial decoration (e.g., spraying with black paint) was undertaken on the workpieces in this study.

\section{Cutting experiments}

Figure 1 presents a schematic overview of the cutting experiment. The flat-sawn LT surface (i.e., bark side) was cut orthogonally by feeding the cutting tool through the workpiece at a constant speed of $5 \mathrm{~mm} / \mathrm{s}$. The cutting edge was perpendicular to the grain. The directions parallel and normal to the cutting direction were designated as $x$ and $y$ directions, respectively. The cutting tools were composed of high-speed steel (SKH51) with rake faces with a $5-\mu \mathrm{m}$ coating of chromium nitride. The wedge angles of the tool were 25,45 , and $65^{\circ}$. The clearance angle was kept constant at $5^{\circ}$ to create the cutting angles $(\theta)$ of 30,50 , and $70^{\circ}$, respectively. The depths of cut $(d)$ were $0.1,0.2$, and $0.3 \mathrm{~mm}$. Cutting was conducted three times for each combination of $\theta, d$, and $\varphi$. Thus, the cutting was conducted $3 \times 3 \times 7 \times 3=189$ times in total. A new workpiece was used for each cutting.

The cutting experiment was recorded using a highspeed camera (VW-6000, KEYENCE). The optical axis of the lens unit (VH-Z150, KEYENCE) was held perpendicular to the LR surface. The frame rate, shutter speed, and image resolution of the camera were $250 \mathrm{fps}, 1 / 2000 \mathrm{~s}$, and $2.2 \times 10^{-3} \mathrm{~mm} /$ pixel, respectively. The field of view of the camera was $1.42 \mathrm{~mm} \times 1.07 \mathrm{~mm}$ (640 pixels $\times 480$ pixels) in the horizontal $(x)$ and vertical $(y)$ directions, respectively. The depth of field of the camera was approximately $0.05 \mathrm{~mm}$. All chip formations recorded in the video clips were classified into four types of chip formation: Type 0 (Flow type), Type I (Cleavage type), Type II (Shear type), or Type III (Compressive type). These types of chip formation were defined by Franz [24, 25] and McKenzie [26].

The fluctuation in the distance from the LR surface to the camera during the recording can result in inaccuracies in the strain measurements. Therefore, the workpiece was cut without a bias angle to avoid application of a lateral cutting force that may cause the fluctuation in the distance from the LR surface to the camera. Inaccuracies and error in the strain measurements may also be caused by Poisson's effect and the vibration of the camera and/or the motorized linear stage. However, the overall degree of error in the strain measurements was found to be negligible in our previous study [1]. 


\section{a Cutting against the grain $\left(\varphi<0^{\circ}\right)$}

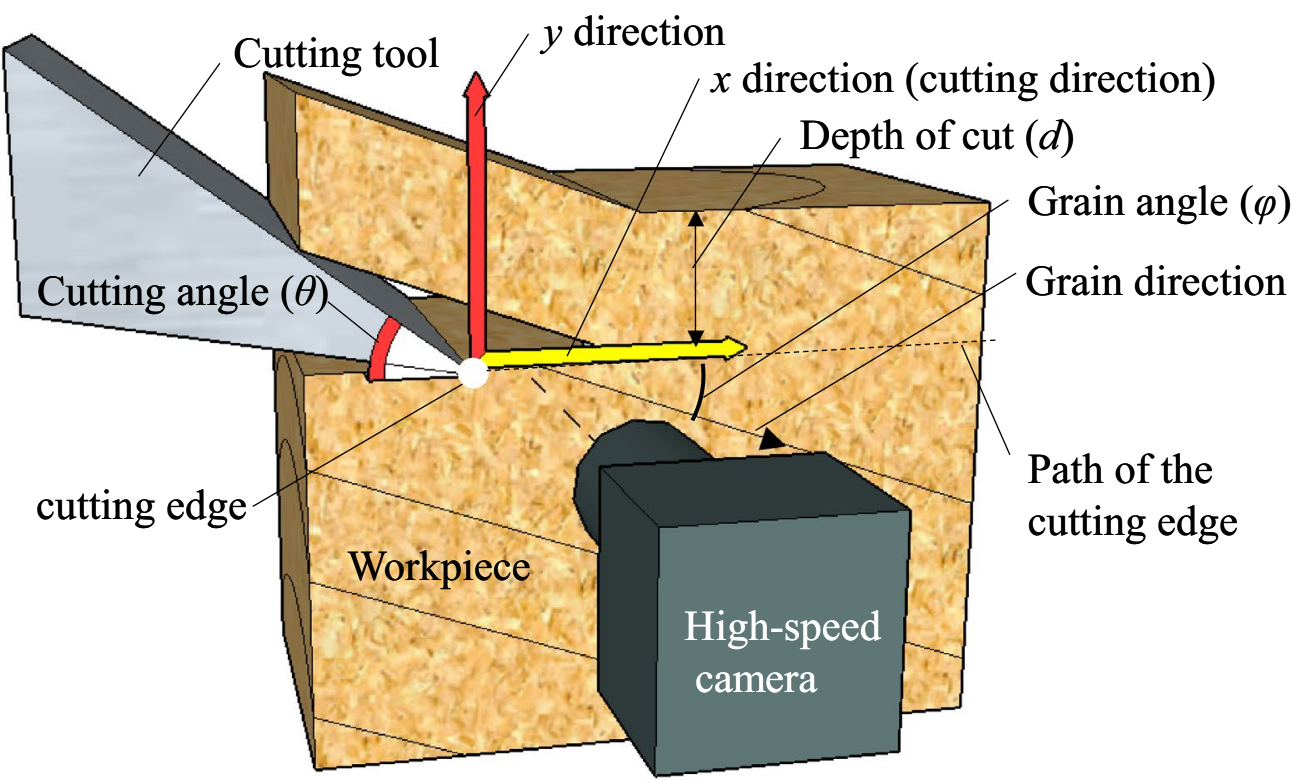

\section{b Cutting with the grain $\left(\varphi>0^{\circ}\right)$}

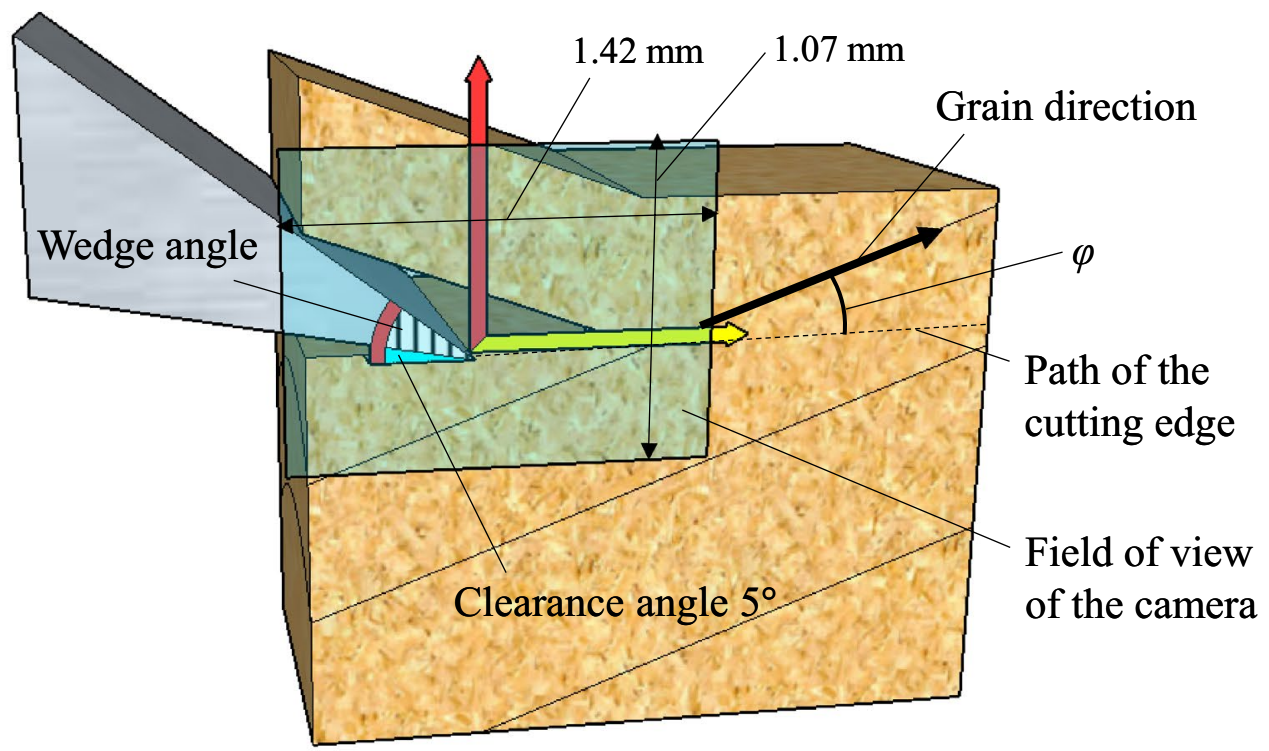

Fig. 1 Schematic overview of the cutting experiment. a Cutting against the grain $\left(\varphi<0^{\circ}\right)$. b Cutting with the grain $\left(\varphi>0^{\circ}\right)$

\section{DIC analysis}

Every video recording was converted into an image sequence of 8-bit grayscale still images using ImageJ software (ver. 1.50e; available online: https://imagej.nih.gov/ ij/download.html) [27]. Grayscale images taken before and during the cutting were designated as reference and target images, respectively. The images were analyzed using the DIC program we coded in MATLAB [28]. 
A region of interest (ROI) used for the measurements was defined in the reference image (the yellow area in Fig. 2). The width ( $x$ direction) of the ROI was 360 pixels $(0.80 \mathrm{~mm})$ and the height $(y$ direction) of the ROI was $140-220$ pixels $(0.31-0.49 \mathrm{~mm})$, respectively. The height of the ROI was adjusted depending on $d$. Latewood was excluded from the ROI. In the target image, the ROI covered the area from 90 pixels $(0.20 \mathrm{~mm})$ behind the cutting edge to 270 pixels $(0.60 \mathrm{~mm})$ ahead of the cutting edge. The bottom of the ROI was located 110 pixels $(0.24 \mathrm{~mm})$ below the path of the cutting edge.

A virtual grid was imposed over the ROI (Fig. 2). The grid points (the white squares in Fig. 2) were placed 20 pixels $(0.04 \mathrm{~mm})$ apart. A reference subset (the red square in Fig. 2) was centered at each grid point. The width and height of the reference subset were both 21 pixels. The DIC program estimated the location of the grid point in the target image by identifying the target subset most similar to the reference subset. The zero-mean normalized cross-correlation coefficient, $C_{\mathrm{ZNCC}}[1,6]$, was used to evaluate the similarity between the reference and target subsets. The value of $C_{\mathrm{ZNCC}}$ was calculated from the grayscale values of the pixels inside the reference and target subsets.

The DIC program calculated the strain parallel to the cutting direction $\left(\varepsilon_{x}\right)$ and normal to the cutting direction $\left(\varepsilon_{y}\right)$, shear strain $\left(\gamma_{x y}\right)$, and maximum principal strain $\left(\varepsilon_{1}\right)$ of the area bound by the four neighboring grid points in the target image. The four types of strain were calculated using the following formulae:

$$
\begin{aligned}
\varepsilon_{x}= & \frac{1}{2}\left[\frac{\left\{\left(x_{b}+u_{b}\right)-\left(x_{a}+u_{a}\right)\right\}-\left(x_{b}-x_{a}\right)}{\left(x_{b}-x_{a}\right)}\right. \\
& \left.+\frac{\left\{\left(x_{d}+u_{d}\right)-\left(x_{c}+u_{c}\right)\right\}-\left(x_{d}-x_{c}\right)}{\left(x_{d}-x_{c}\right)}\right],
\end{aligned}
$$

$$
\begin{aligned}
\varepsilon_{y}= & \frac{1}{2}\left[\frac{\left\{\left(y_{a}+v_{a}\right)-\left(y_{c}+v_{c}\right)\right\}-\left(y_{a}-y_{c}\right)}{\left(y_{a}-y_{c}\right)}\right. \\
& \left.+\frac{\left\{\left(y_{b}+v_{b}\right)-\left(y_{d}+v_{d}\right)\right\}-\left(y_{b}-y_{d}\right)}{\left(y_{b}-y_{d}\right)}\right], \\
\gamma_{x y}= & \frac{1}{2}\left[\left\{\begin{array}{c}
\frac{\left(y_{d}+v_{d}\right)-\left(y_{c}+v_{c}\right)}{\left(x_{d}+u_{d}\right)-\left(x_{c}+u_{c}\right)} \\
+\frac{\left(y_{b}+v_{b}\right)-\left(y_{a}+v_{a}\right)}{\left(x_{b}+u_{b}\right)-\left(x_{a}+u_{a}\right)}
\end{array}\right\}+\left\{\begin{array}{c}
\frac{\left(x_{a}+u_{a}\right)-\left(x_{c}+u_{c}\right)}{\left(y_{a}+v_{a}\right)-\left(y_{c}+v_{c}\right)} \\
+\frac{\left(x_{b}+u_{b}\right)-\left(x_{d}+u_{d}\right)}{\left(y_{b}+v_{b}\right)-\left(y_{d}+v_{d}\right)}
\end{array}\right\}\right], \\
\varepsilon_{1}= & \frac{\varepsilon_{x}+\varepsilon_{y}}{2}+\sqrt{\left(\frac{\varepsilon_{x}-\varepsilon_{y}}{2}\right)^{2}+\gamma_{x y}^{2},}
\end{aligned}
$$

where $x_{k}$ and $y_{k}(k=a, b, c, d)$ are the $x$ and $y$ coordinates of the four grid points in the reference image in Fig. 3, respectively; and $u_{k}$ and $v_{k}(k=a, b, c, d)$ are the displacement components (between the reference and target images) of the four grid points in the $x$ and $y$ directions. The displacement components, $u$ and $v$, were estimated with a sub-pixel level accuracy using a coarse-to-fine algorithm [1,2]. The smallest measureable $\varepsilon_{x}, \varepsilon_{y}$, and $\gamma_{x y}$ of the square element were approximately $0.08 \%$ [1]. The precision (i.e., the error rate) and the accuracy (i.e., the coefficient of variation) of the DIC program were approximately $\pm 2 \%$ and $-17 \%$, respectively [1].

\section{Results and discussion \\ Relationships between type of chip formation and grain angle}

Table 1 presents the relationships of type of chip formation [24-26] with $\varphi, \theta$, and $d$. There were some combinations of $\varphi, \theta$, and $d$ that did not result in any

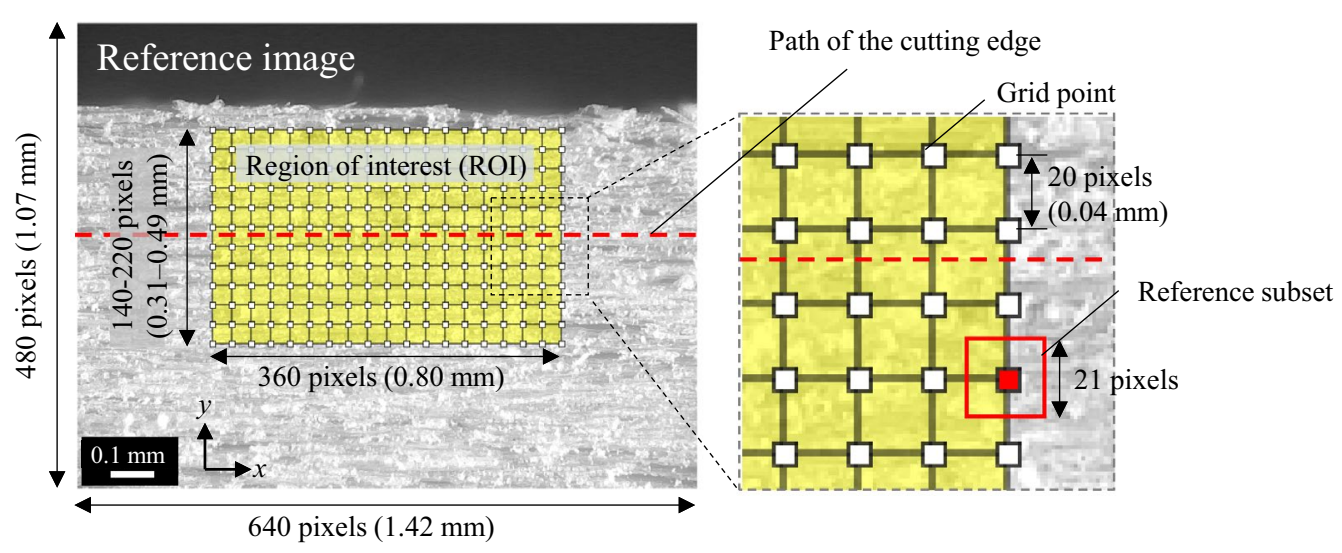

Fig. 2 The region of interest (yellow area) and the grid points (white squares) allocated in a reference image 


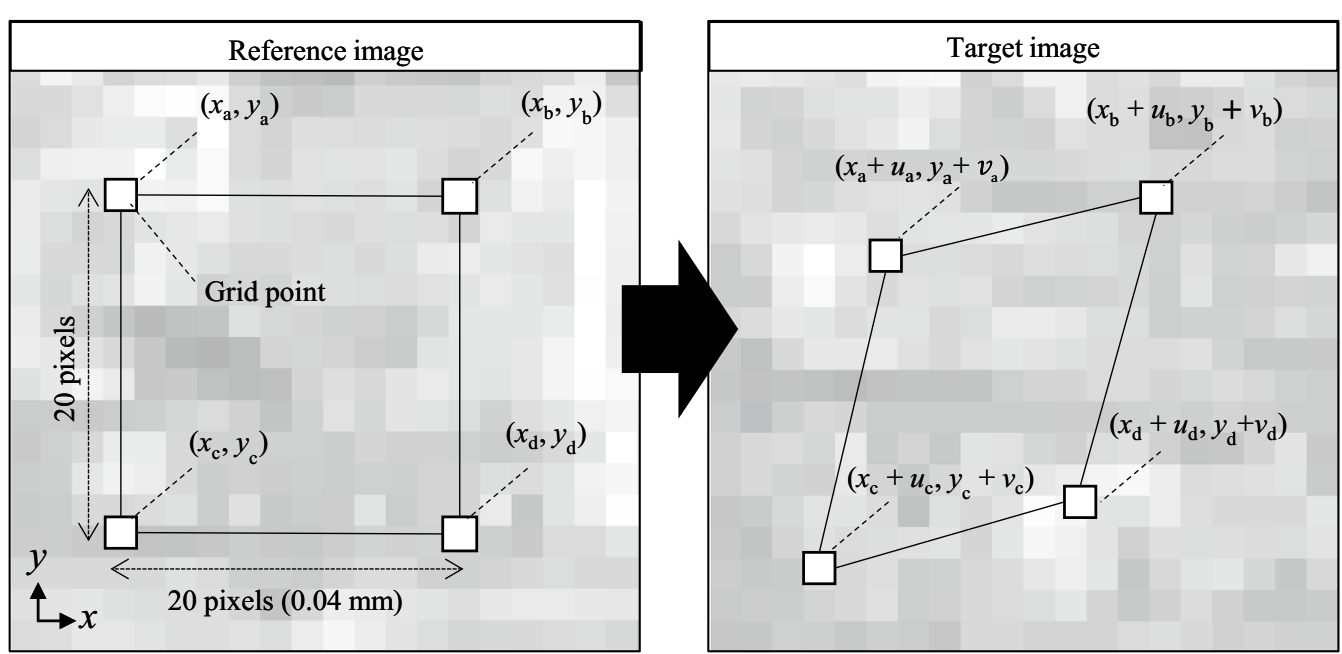

Fig. 3 The grid points in the reference and target images with their $x$ and $y$ coordinates defined

Table 1 Relationships of types of chip formation (Types 0 , I, II, and III) with the cutting angle ( $\theta$ ), the depth of cut (d), and the grain angle $(\varphi)$

\begin{tabular}{|c|c|c|c|c|c|c|c|c|}
\hline \multirow[t]{2}{*}{ Cutting angle $(\theta)$} & \multirow{2}{*}{$\begin{array}{l}\text { Depth of cut }(d) \\
(\mathrm{mm})\end{array}$} & \multicolumn{7}{|c|}{ Grain angle $(\varphi)$} \\
\hline & & $-15^{\circ}$ & $-10^{\circ}$ & $-5^{\circ}$ & $0^{\circ}$ & $+5^{\circ}$ & $+10^{\circ}$ & $+15^{\circ}$ \\
\hline \multirow[t]{3}{*}{$30^{\circ}$} & 0.1 & 0 & 0 & 0 & 0 & 0 & 0 & 0 \\
\hline & 0.2 & 0 & - & - & 0 & । & 1 & । \\
\hline & 0.3 & - & - & - & $0 / 1$ & । & I & I \\
\hline \multirow[t]{3}{*}{$50^{\circ}$} & 0.1 & $\|$ & $\|$ & $|/| \mid$ & $|/| \mid$ & $\|$ & $\|$ & $\|$ \\
\hline & 0.2 & $\|$ & $\|$ & $|/| \mid$ & । & $|/| \mid$ & $|/| \mid$ & $\|$ \\
\hline & 0.3 & $\|$ & I & $|/| \mid$ & । & I & $|/| \mid$ & 1 \\
\hline \multirow[t]{3}{*}{$70^{\circ}$} & 0.1 & $\|/\| \|$ & $\|/\| \|$ & $\|$ & $\|$ & $\|$ & $\|$ & III \\
\hline & 0.2 & $\|$ & $\|$ & $\|$ & $\|/\| \|$ & $\|/\| I \|$ & III & III \\
\hline & 0.3 & $\|$ & $\|$ & $\|$ & III & III & III & III \\
\hline
\end{tabular}

The dashes (-) indicate where the strain near the cutting edge could not be measured due to the failure of the workpiece. This was caused by cleavage occurring where the cutting tool was first cut into the workpiece, and thus, the cutting could not be conducted properly

chip formation type. In these cases, the cutting was not properly implemented where the workpiece failed and the cleavage occurred when the cutting tool initially cut into the workpiece. Thus, the strain near the cutting edge could not be measured. When $\theta$ was $30^{\circ}$, the resulting chip formation was classified as Type 0 (Flow type) or Type I (Cleavage type). The chip was produced by a cleavage ahead of the cutting edge. The cleavage tended to travel further ahead of the tool with increasing $d$. Subsequently, the chip formation type changed from Type 0 to Type I as $d$ increased. When $\theta$ was $50^{\circ}$, the chip formation was Type I when $\varphi$ was near $0^{\circ}$. Conversely, chip formation was Type II (Shear type) when the cutting was with or against the grain. As $d$ increased, Type I chip formation tended to occur independently of $\varphi$. When $\theta$ was at $70^{\circ}$, the chip formation changed from Type II to Type III (Compressive type) with increasing $\varphi$.

\section{Relationships between the strain distribution and the grain angle}

Figures 4, 5, 6, and 7 demonstrate the examples of the distributions of $\varepsilon_{x}, \varepsilon_{y}, \gamma_{x y}$, and $\varepsilon_{1}$, respectively $(d=0.2 \mathrm{~mm})$. The plus symbols in the images represent the grid points. The square elements that contain more than one grid point with $C_{\mathrm{ZNCC}} \leq 0.5$ are not colored because of potential error in the calculation of the displacement components. All types of strain were found to be distributed in 


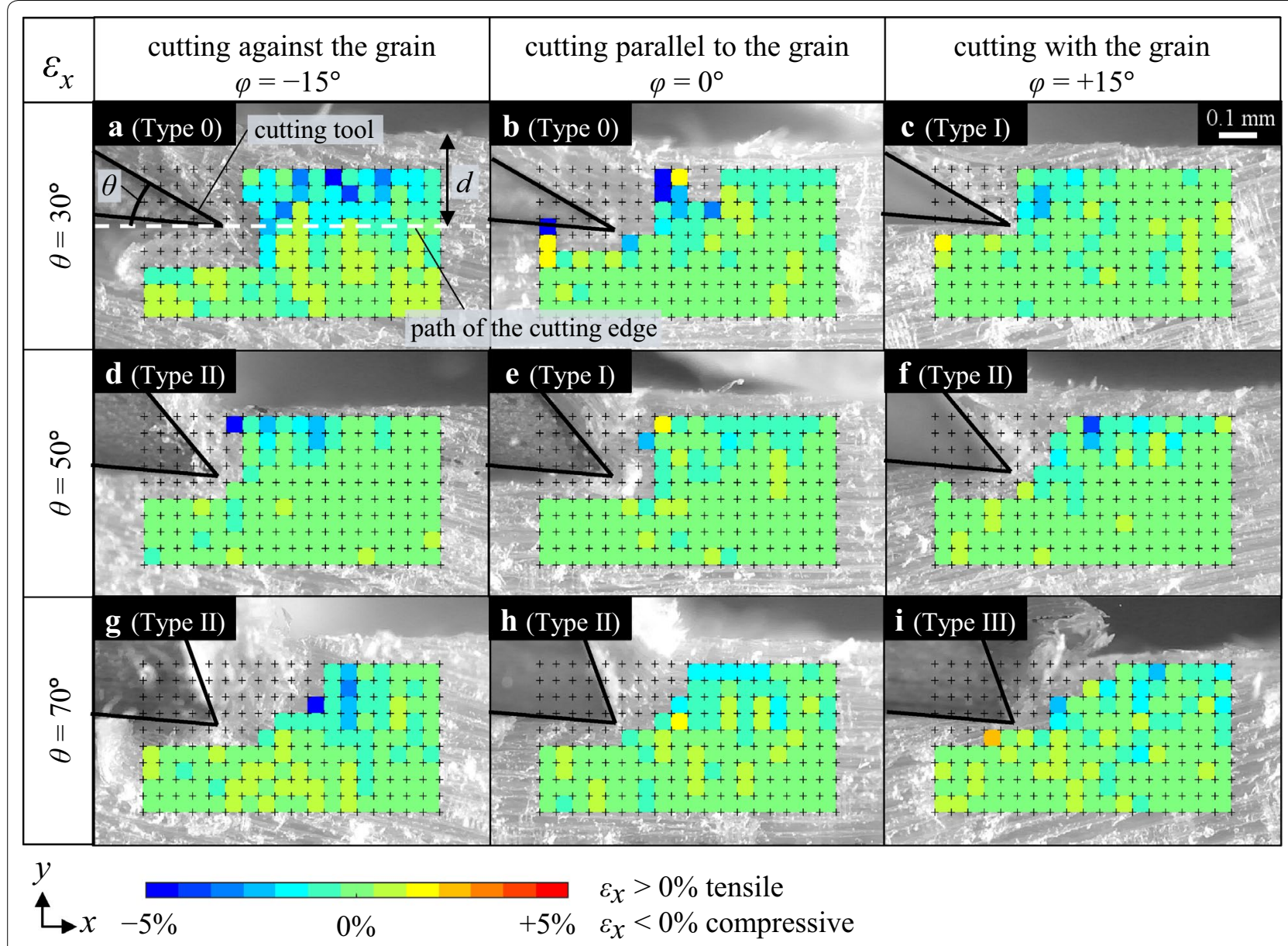

Fig. 4 The distribution of $\varepsilon_{x}$ and its relationships with the grain angle $(\varphi)$ and the cutting angle $(\theta)(d=0.2 \mathrm{~mm})$

the area within $0.5 \mathrm{~mm}$ away from the cutting edge for all values of $\varphi, \theta$, or $d$. The relationships between the distributions of $\varepsilon_{x}, \varepsilon_{y}$, and $\gamma_{x y}$ with $\theta$ and $d$ where the cutting was parallel to the grain $\left(\varphi=0^{\circ}\right)$ were similar to those from our previous study [1]. The relationships between each type of strain and the grain angle are described below. The characteristics of their relationships were similar to those found for the other depths of cut; although the relationships were stronger with increasing $d$.

\section{Strain parallel to the cutting direction $\left(\varepsilon_{x}\right)$}

Figure 4 presents the relationships of $\varepsilon_{x}$ with $\varphi$ and $\theta$. Compressive $\varepsilon_{x}$ was detected in the area above the path of the cutting edge, where material should be removed as a chip (regardless of $\varphi$ and $\theta$ ). This was because the area was compressed by the rake face of the tool. The parallel cutting force component was generally greater than the normal cutting force component, thus considerable compressive stress should be distributed ahead of the tool. The range of transmission of compressive $\varepsilon_{x}$ appeared to decrease as $\varphi$ increased. In other words, the range of transmission of compressive $\varepsilon_{x}$ appeared to be smaller when the cutting was with the grain (the right column in Fig. 4) than when the cutting was against the grain (the left column in Fig. 4). However, its relationship with $\varphi$ was unclear.

\section{Strain normal to the cutting direction $\left(\varepsilon_{y}\right)$}

Figure 5 presents the relationships of $\varepsilon_{y}$ with $\varphi$ and $\theta$. When $\theta$ was $30^{\circ}$ (the top row in Fig. 5), tensile $\varepsilon_{y}$ was detected ahead of the tool which appeared to generate cleavage ahead of the cutting tool. The range of its transmission reduced with increasing $\varphi$. The tensile $\varepsilon_{y}$ tended to extend beneath the path of the cutting edge when cutting against the grain (Fig. 5a). Conversely, it tended to extend above the path of the cutting edge when the cutting was with the grain (Fig. $5 \mathrm{c}$ ). This suggests that the direction of the cleavage propagation was affected by the grain angle. Compressive $\varepsilon_{y}$ was detected above the path 


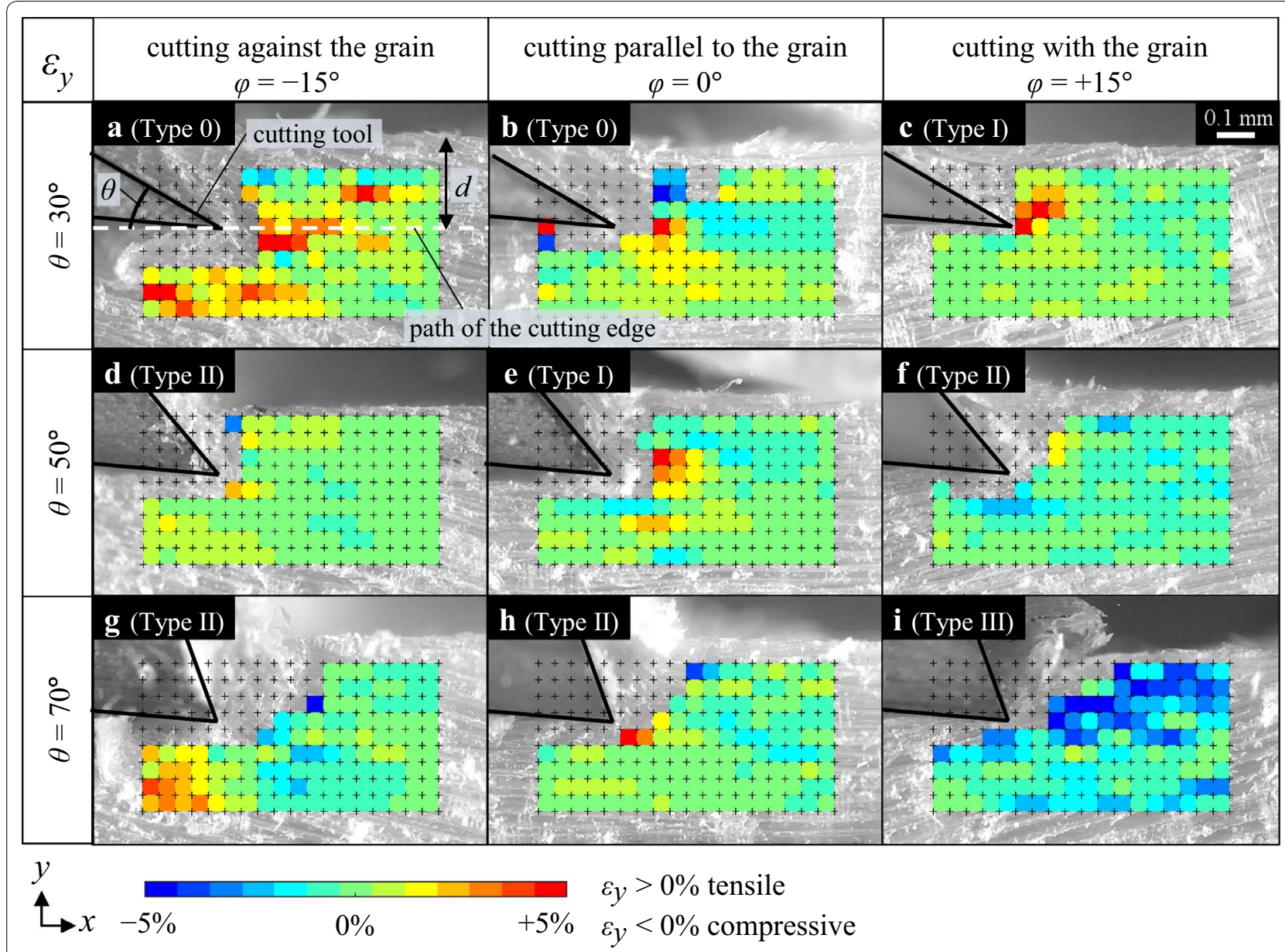

Fig. 5 The distribution of $\varepsilon_{y}$ and its relationships with the grain angle $(\varphi)$ and the cutting angle $(\theta)(d=0.2 \mathrm{~mm})$

of the cutting edge when the cutting was parallel to the grain (Fig. 5b).

When $\theta$ was $50^{\circ}$ (the middle row in Fig. 5), the range of transmission of tensile $\varepsilon_{y}$ ahead of the tool reduced by cutting with or against the grain. The tensile $\varepsilon_{y}$ when cutting against the grain (Fig. $5 \mathrm{~d}$ ) was lower than when $\theta$ was $30^{\circ}$ (Fig. 5a). When $\theta$ was $70^{\circ}$ (the bottom row in Fig. 5), compressive $\varepsilon_{y}$ was detected in the area above the path of the cutting edge, especially when cutting with the grain (Fig. 5i).

Torn grain was appeared to be most likely to occur when $\varphi<0^{\circ}$ and $\theta=30^{\circ}$ (Fig. 5a). This was because tensile $\varepsilon_{y}$, which generates cleavage along the grain, was detected beneath the path of the cutting edge. The tensile $\varepsilon_{y}$ decreased when $\theta$ was $50^{\circ}$ (Fig. $5 \mathrm{~d}$ ), where the chip formation changed from Type I to Type II.

\section{Shear strain $\left(\gamma_{x y}\right)$}

Figure 6 presents the relationships of $\gamma_{x y}$ with $\varphi$ and $\theta$. Shear strain was detected in the area above the path of the cutting edge for all $\varphi$ and $\theta$ values and their combinations. When $\theta$ was $30^{\circ}$ (top row in Fig. 6), the direction of $\gamma_{x y}$ varied depending on $\varphi$. Negative $\gamma_{x y}$ tended to be detected when cutting against the grain (Fig. 6a). On the other hand, $\gamma_{x y}$ tended to be positive when cutting with the grain (Fig. 6c). The negative $\gamma_{x y}$ may cause the chip to shorten in $\mathrm{L}$ direction and to become thicker than $d$; whereas the positive $\gamma_{x y}$ may cause the chip to elongate in $\mathrm{L}$ direction and to become thinner than $d$ [1]. The shrinkage and elongation of the chip may be affected by the grain angle.

When $\theta$ was $50^{\circ}$ (middle row in Fig. 6), $\gamma_{x y}$ was negative above the path of the cutting edge while cutting with the grain (Fig. 6f), in contrast to the positive $\gamma_{x y}$ when $\theta$ was $30^{\circ}$ (Fig. 6c). This indicated that the chip produced with a cutting angle of $50^{\circ}$ (Type II) had a shorter length than that produced with a cutting angle of $30^{\circ}$ (Type I). Our previous study [1] also showed that the chip associated with Type II chip formation was shorter than that of Type I. 


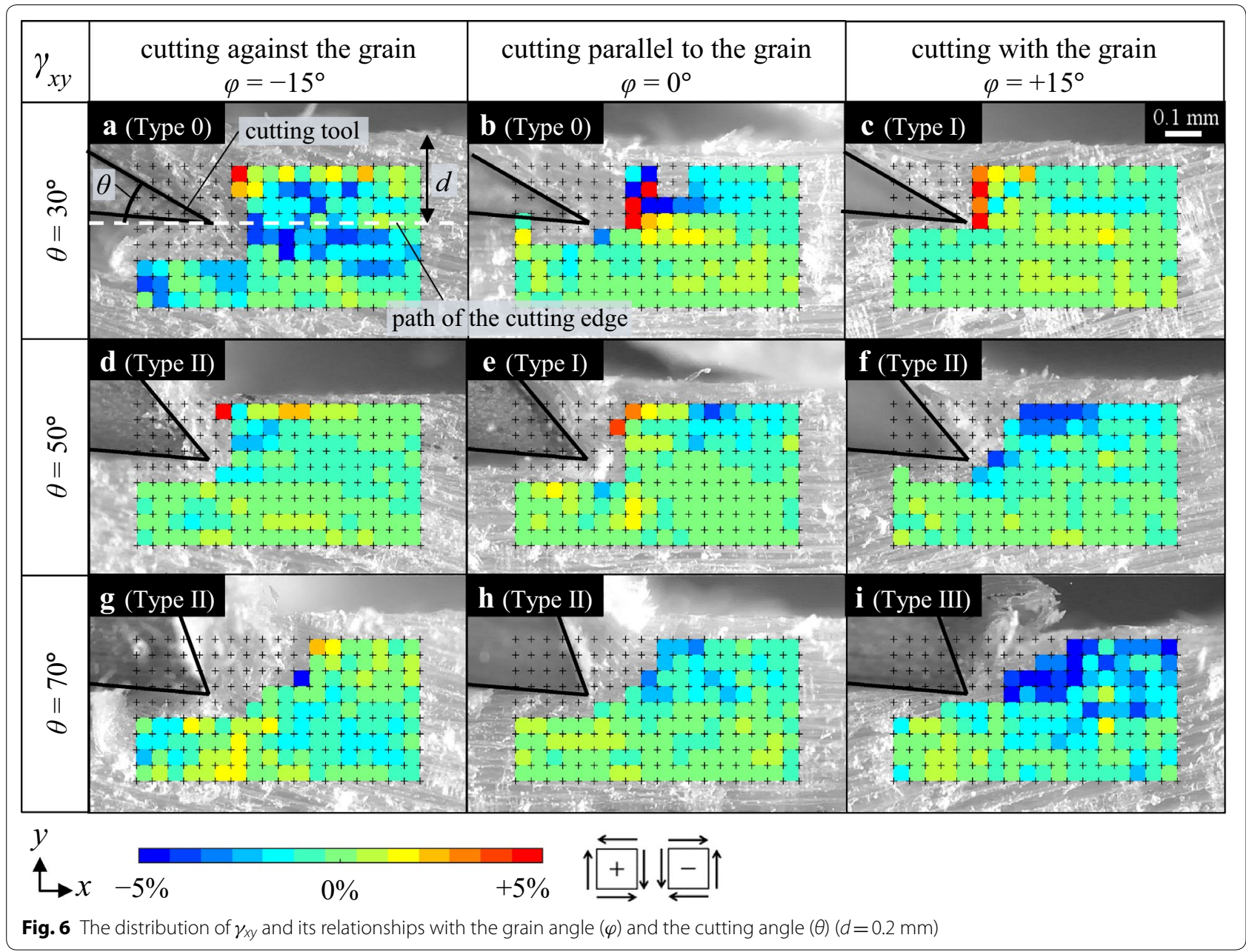

When $\theta$ was $70^{\circ}$, the relationship between $\gamma_{x y}$ and $\varphi$ (bottom row in Fig. 6) was similar to that obtained where $\theta$ was $50^{\circ}$ (middle row in Fig. 6). When cutting with the grain, the range of transmission of the negative $\gamma_{x y}$ (Fig. 6i) was greater than that detected when $\theta$ was $50^{\circ}$ (Fig. 6f).

\section{Maximum principal strain $(\varepsilon \mathcal{V})$}

Figure 7 represents the relationships of $\varepsilon_{1}$ with $\varphi$ and $\theta$. When $\theta$ was $30^{\circ}$ (top row in Fig. 7), the range of transmission of $\varepsilon_{1}$ expanded with decreasing $\varphi$. For cutting with the grain (Fig. 7c), the strain of $5 \%$ or larger was distributed within $0.1 \mathrm{~mm}$ from the cutting edge. In this situation, the chip should split very close to the cutting edge, and the cutting should be properly controlled. The strain occurring beneath the path of the cutting edge may lead to machining defects if it remains after cutting [2]. Thus, cutting with the grain $\left(\varphi>0^{\circ}\right)$ was deemed preferable with consideration for the quality of the finished surface.

When $\theta$ was $50^{\circ}$ (middle row in Fig. 7), the distribution of $\varepsilon_{1}$ was not greatly affected by $\varphi$. For cutting against the grain $\left(\varphi<0^{\circ}\right)$, a cutting angle of $50^{\circ}$ (Fig. $7 \mathrm{~d}$ ) gave a smaller range of transmission of $\varepsilon_{1}$ than that given by a cutting angle of $30^{\circ}$ (Fig. 7a). This indicated that a cutting angle of $50^{\circ}$ is preferable to an angle of $30^{\circ}$ for controlling the chip formation for cutting against the grain. When $\theta$ was $70^{\circ}$ (bottom row in Fig. 7), $\varepsilon_{1}$ was mainly distributed beneath the path of the cutting edge for cutting against the grain (Fig. $7 \mathrm{~g}$ ); whereas $\varepsilon_{1}$ was mainly distributed above the path of the cutting edge for cutting with the grain (Fig. 7i). This also tended to occur when $\theta$ was $30^{\circ}$.

The maximum principal strain distributed ahead of the tool We evaluated the extent of the strain in the area ahead of the tool and its relationship with the grain angle. For simplicity, only $\varepsilon_{1}$ was evaluated instead of discussing all different types of strain. We selected $\varepsilon_{1}$ because it was calculated from the other types of strain, and therefore, it should be representative to the other types of strain. We calculated the average $\varepsilon_{1}$ detected in an area ahead of the cutting tool (the green area in Fig. 8) and designated this as $\varepsilon_{1 \_ \text {ahead. }}$. The dimensions 


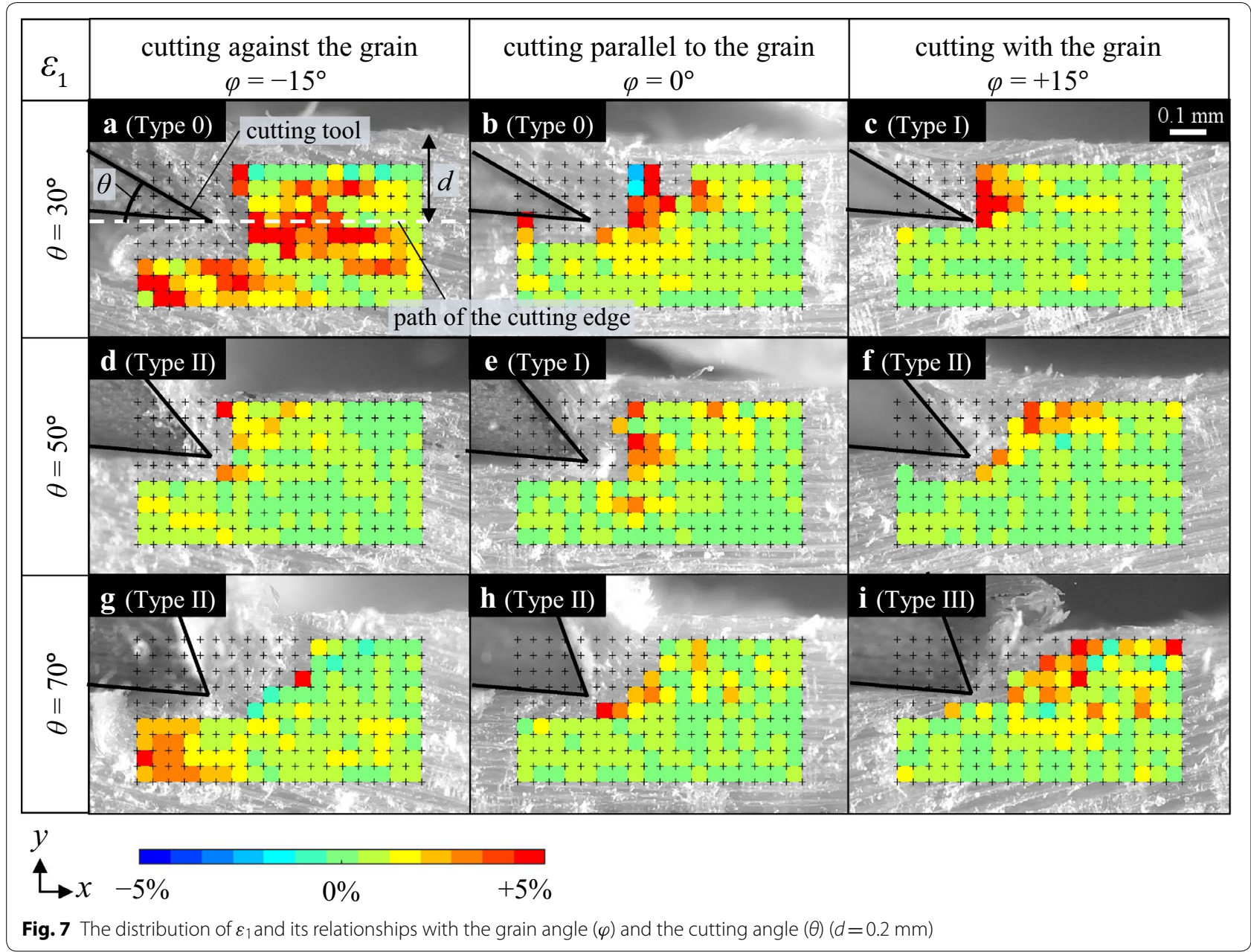

of the green area are 140 pixels $\times 140-220$ pixels $(0.31 \mathrm{~mm} \times 0.31-0.49 \mathrm{~mm})$ in the $x$ and $y$ directions, respectively. The left-side edge of the green area was placed 50 pixels $(0.11 \mathrm{~mm})$ ahead of the cutting edge and the bottom of the green area was placed 110 pixels $(0.24 \mathrm{~mm})$ below the path of the cutting edge. The height (i.e., $y$ direction) of the green area was adjusted according to $d$. We conducted three cutting replicates for each combination of $\varphi, \theta$, and $d$; therefore, three sets of strain data of $\varepsilon_{1 \text { ahead }}$ were obtained for each combination. We calculated the average of the three sets of strain data for $\varepsilon_{1 \_ \text {ahead }}$, and designated it as $\overline{\varepsilon_{1 \_ \text {ahead }}}$.

Figure 8 presents the relationships of $\overline{\varepsilon_{1 \_ \text {ahead }}}$ with $\varphi$, $\theta$, and $d$. The strain ahead of the tool was minimized when $\theta$ was $50^{\circ}$ and $+5^{\circ} \leq \varphi \leq+10^{\circ}$ for all values of $d$. With these parameters, most of the strains were concentrated very close at the cutting edge; therefore, the chip always split along the path of the cutting edge without deviation. This is ideal as this would provide the most control for the cutting.

\section{Conclusions}

The strain distribution within $0.5 \mathrm{~mm}$ of the cutting edge in the orthogonal cutting with and against the grain was measured using the DIC method in an investigation of the effect of grain angle $\left(-15^{\circ} \leq \varphi \leq+15^{\circ}\right)$ on strain distribution near the cutting edge. The results were as follows:

- Compressive $\varepsilon_{x}$ was detected in the area above the path of the cutting edge. However, its relationship to $\varphi$ was unclear in this study.

- Tensile $\varepsilon_{y}$ was detected in the area ahead of the tool when $\theta$ was $30^{\circ}$. This tensile $\varepsilon_{y}$ increased with decreasing $\varphi$. The $\varepsilon_{y}$ ahead of the tool changed to 

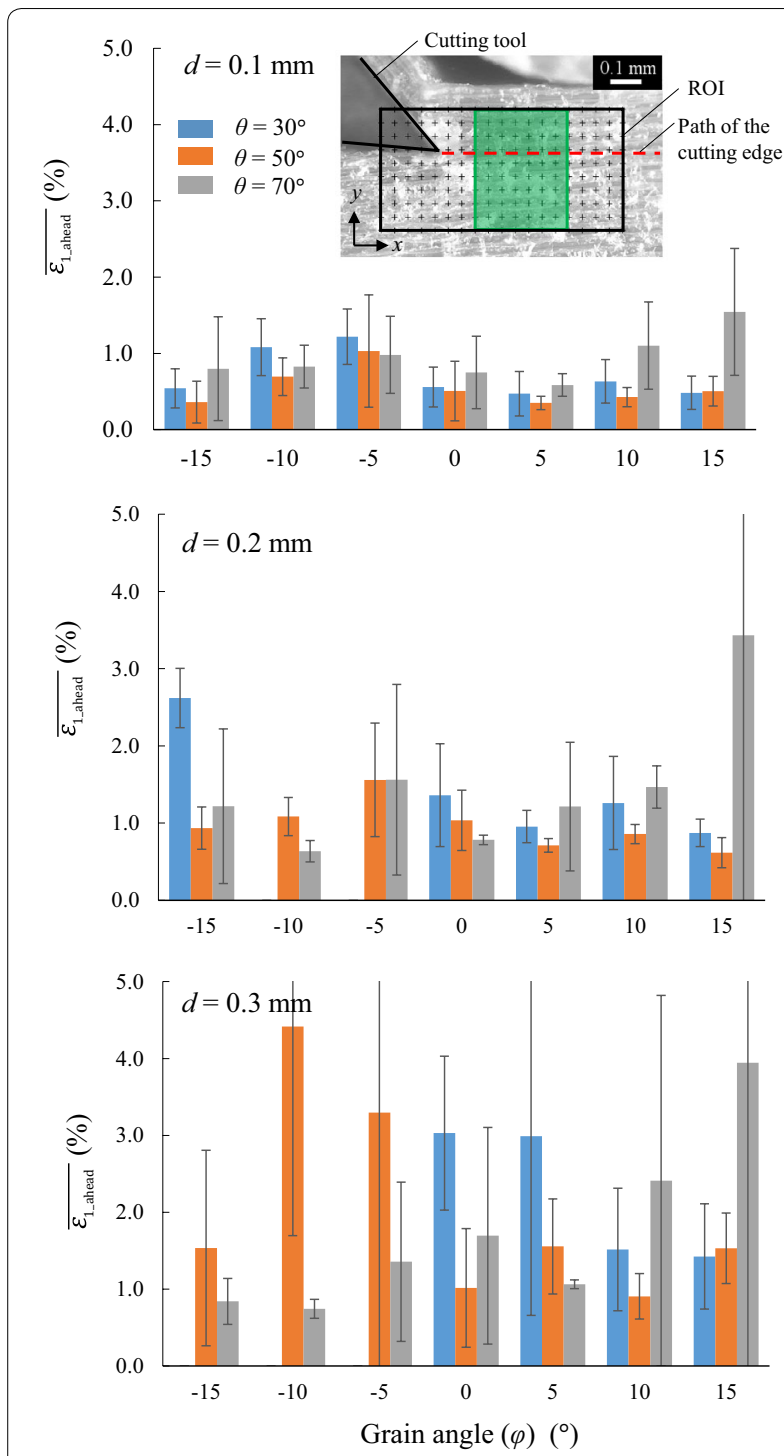

Fig. 8 The relationships of $\varepsilon$ distributed ahead of the cutting tool $\left(\varepsilon_{1}\right.$ _ahead $)$ with $\varphi, \theta$, and $d$. The error bars represent the standard deviations. The strain data could not be obtained for some combinations of $\varphi, \theta$, and $d$ (as in Table 1)

compressive as $\theta$ increased. The compressive $\varepsilon_{y}$ increased with increasing $\varphi$ when $\theta$ was $70^{\circ}$.

- Negative $\gamma_{x y}$ was detected above the path of the cutting edge, especially when $\theta \geq 50^{\circ}$. The negative $\gamma_{x y}$ increased with increasing $\varphi$.

- A cutting angle of $50^{\circ}$ gave a smaller range of transmission of $\varepsilon_{1}$ than those given by the other cutting angles, especially when cutting against the grain.

- When $\theta$ was $50^{\circ}$ and $+5^{\circ} \leq \varphi \leq+10^{\circ}, \varepsilon_{1}$ ahead of the tool was minimized, and the cutting was considered to be optimally controlled.

\section{Acknowledgements}

The authors would like to express their sincere thanks to the Kanefusa Corporation for providing the cutting tools and to Dr. Koji Murata (Kyoto University) for giving us technical advice about the DIC method. Part of this article was presented at the 68th Annual Meeting of the Japan Wood Research Society, Fukuoka, Japan, March 2018

\section{Authors' contributions}

YM designed the DIC program and conducted experiments and DIC analysis, and was in charge of drafting the manuscript. YM owns the copyright of the DIC program. YFujii supported YM for the research design and analysis of data. All other authors supported the work from research design, cutting experiments, DIC analysis, and paper finishing. All authors read and approved the final manuscript.

\section{Funding}

Not applicable.

\section{Availability of data and materials}

The datasets used and/or analyzed during the current study are available from the corresponding author on reasonable request.

Ethics approval and consent to participate

Not applicable.

\section{Consent for publication}

Not applicable.

\section{Competing interests}

The authors declare that they have no competing interests.

\section{Author details}

${ }^{1}$ Forestry and Forest Products Research Institute, 1 Matsunosato, Tsukuba, Ibaraki 305-8687, Japan. ${ }^{2}$ Graduate School of Agriculture, Kyoto University, Kitashirawakaoiwake-cho, Sakyo-Ku, Kyoto, Kyoto 606-8502, Japan.

Received: 22 October 2018 Accepted: 23 August 2019

Published online: 04 September 2019

\section{References}

1. Matsuda Y, Fujiwara Y, Fujii Y (2018) Strain analysis near the cutting edge in orthogonal cutting of hinoki (Chamaecyparis obtusa) using a digital image correlation method. J Wood Sci 64(5):566-577

2. Matsuda Y, Fujiwara Y, Murata K, Fujii Y (2017) Residual strain analysis with digital image correlation method for subsurface damage evaluation of hinoki (Chamaecyparis obtusa) finished by slow-speed orthogonal cutting. J Wood Sci 63(6):615-624

3. Peters WH, Ranson WF (1982) Digital imaging techniques in experimental stress analysis. Opt Eng 21(3):427-431

4. Sutton MA, Wolters WJ, Peters WH, Ranson WF, McNeill SR (1983) Determination of displacements using an improved digital correlation method. Image Vis Comput 1(3):133-139

5. Sutton MA, Orteu JJ, Schreier HW (2009) Image correlation for shape, motion and deformation measurements: basic concepts, theory and applications. Springer, New York

6. Pan B, Qian K, Xie H, Asundi A (2009) Two-dimensional digital image correlation for in-plane displacement and strain measurement: a review. Meas Sci Technol. https://doi.org/10.1088/0957-0233/20/6/062001

7. Pan B, Lu Z, Xie H (2010) Mean intensity gradient: an effective global parameter for quality assessment of the speckle patterns used in digital image correlation. Opt Lasers Eng 48:469-477

8. Choi D, Thorpe JL, Hanna RB (1991) Image analysis to measure strain in wood and paper. Wood Sci Technol 25:251-262

9. Murata K, Masuda M, Ichimaru M (1999) Analysis of radial compression behavior of wood using digital image correlation method. Mokuzai Gakkaishi 45(5):375-381 (in Japanese)

10. Hellström LM, Gradin PA, Carlberg T (2008) A method for experimental investigation of the wood chipping process. Nordic Pulp Pap Res J 23(3):339-342 
11. Nagai H, Murata K, Nakano T (2011) Strain analysis of lumber containing a knot during tensile failure. J Wood Sci 57:114-118

12. Keunecke D, Novosseletz K, Lanvermann C, Mannes D, Niemz P (2012) Combination of $X$-ray and digital image correlation for the analysis of moisture-induced strain in wood: opportunities and challenges. Eur J Wood Prod 70:407-413

13. Matsuda Y, Fujiwara Y, Fujii Y (2015) Observation of machined surface and subsurface structure of hinoki (Chamaecyparis obtusa) produced in slowspeed orthogonal cutting using X-ray computed tomography. J Wood Sci 61(2):128-135

14. Stewart HA (1983) A model for predicting wood failure with respect to grain angle in orthogonal cutting. Wood Fiber Sci 15(4):317-325

15. Yamashita A (1977) Studies on mechanism of orthogonal cutting of wood with Japanese plane I: effects of distance between knife edge and cap iron edge and depth of cut on surface quality in cutting against the grain. Mokuzai Gakkaishi 23(2):82-88 (in Japanese)

16. Kinebuchi Y (1979) Studies on the linear cutting in wood machining (I). J Fac Educ Shinshu Univ 41:211-224 (in Japanese)

17. Kinoshita N (1960) Studies on precise wood machining. Rep Inst Phys Chem Res 36(5):486-557 (in Japanese)

18. Stewart HA (1969) Effect of cutting direction with respect to grain angle on the quality of machined surface, tool force components, and cutting friction coefficient. For Prod J 19(3):43-46

19. Mori M (1969) An analysis of cutting work in peripheral milling of wood $I$ : on the work done by a knife in up-milling parallel to wood grain. Mokuzai Gakkaishi 15(3):93-98 (in Japanese)

20. Mori M (1971) An analysis of cutting work in peripheral milling of wood III: variation of cutting force in inside cutting of wood with router-bit. Mokuzai Gakkaishi 17(10):437-442 (in Japanese)
21. Sugiyama S (2003) Studies on quantification of sensuous sharpness and mechanical sharpness of wood cutting tools XXIV: effects of workpiece grain-angle upon stress distribution and frictional coefficient on tool rake-face in wood cutting (1). Bull Fac Educ Nagasaki Univ Nat Sci 69:33-38 (in Japanese)

22. McKenzie WM, Hawkins BT (1966) Quality of near longitudinal wood surface formed by inclined cutting. For Prod J 16(7):35-38

23. Stewart HA (1971) Chip formation when orthogonally cutting wood against grain. Wood Sci 3(4):193-203

24. Franz NC (1955) Analysis of chip formation in wood machining. For Prod J 5(5):332-336

25. Franz NC (1958) An analysis of the wood-cutting process. Dissertation, University of Michigan

26. McKenzie WM (1967) The basic wood cutting process. In: Proceedings of the second wood machining seminar, Richmond, 10-11 October 1967, pp 3-8

27. Schneider CA, Rasband WS, Eliceiri KW (2012) NIH Image to ImageJ: 25 years of image analysis. Nat Methods 9:671-675

28. MATLAB Release (2017) The MathWorks, Inc., Natick, Massachusetts, USA

\section{Publisher's Note}

Springer Nature remains neutral with regard to jurisdictional claims in published maps and institutional affiliations.

\section{Submit your manuscript to a SpringerOpen ${ }^{\odot}$ journal and benefit from:}

- Convenient online submission

- Rigorous peer review

- Open access: articles freely available online

- High visibility within the field

- Retaining the copyright to your article

Submit your next manuscript at $\mathbf{s p r i n g e r o p e n . c o m ~}$ 